\title{
Impact of the integration of proton magnetic resonance imaging spectroscopy to PI-RADS 2 for prediction of high grade and high stage prostate cancer
}

Impacto da incorporação da espectroscopia por ressonância magnética ao PI-RADS 2 para a predição de câncer de próstata de alto grau e de estágio avançado

Michael S. Leapman ${ }^{1}$, Zhen J. Wang ${ }^{2}$, Spencer C. Behr ${ }^{2}$, John Kurhanewicz ${ }^{3}$, Ronald J. Zagoria ${ }^{2}$, Peter R. Carroll ${ }^{4}$, Antonio C. Westphalen ${ }^{5}$

Leapman MS, Wang ZJ, Behr SC, Kurhanewicz J, Zagoria RJ, Carroll PR, Westphalen AC. Impact of the integration of proton magnetic resonance imaging spectroscopy to PI-RADS 2 for prediction of high grade and high stage prostate cancer. Radiol Bras. 2017 Set/Out;50(5):299-307.

Abstract Objective: To compare the predictions of dominant Gleason pattern $\geq 4$ or non-organ confined disease with Prostate Imaging Reporting and Data System (PI-RADS v2) with or without proton magnetic resonance spectroscopic imaging $\left({ }^{1} \mathrm{H}-\mathrm{MRSI}\right)$.

Materials and Methods: Thirty-nine men underwent 3-tesla endorectal multiparametric MRI including ${ }^{1} \mathrm{H}$-MRSI and prostatectomy. Two radiologists assigned PI-RADS v2 and ${ }^{1} \mathrm{H}-\mathrm{MRSI}$ scores to index lesions. Statistical analyses used logistic regressions, receiver operating characteristic (ROC) curves, and 2x2 tables for diagnostic accuracies.

Results: The sensitivity and specificity of ${ }^{1} \mathrm{H}-\mathrm{MRSI}$ and PI-RADS v2 for high-grade prostate cancer (PCa) were $85.7 \%$ (57.1\%) and 92.9\% (100\%), and 56\% (68.0\%) and 24.0\% (24.0\%). The sensitivity and specificity of ${ }^{1} \mathrm{H}-\mathrm{MRSI}$ and PI-RADS v2 for extra-prostatic extension (EPE) were $64.0 \%$ (40\%) and $20.0 \%$ (48\%), and 50.0\% (57.1\%) and 71.4\% (64.3\%). The area under the ROC curves (AUC) for prediction of high-grade prostate cancer were 0.65 and 0.61 for PI-RADS v2 and 0.72 and 0.70 when combined with ${ }^{1} \mathrm{H}-\mathrm{MRSI}$ (readers 1 and 2, $p=0.04$ and 0.21). For prediction of EPE the AUC were 0.54 and 0.60 for PI-RADS v2 and 0.55 and 0.61 when combined with ${ }^{1} \mathrm{H}-\mathrm{MRSI}(p>0.05)$.

Conclusion: ${ }^{1} \mathrm{H}-\mathrm{MRSI}$ might improve the discrimination of high-grade prostate cancer when combined to PI-RADS v2, particularly for PI-RADS v2 score 4 lesions, but it does not affect the prediction of EPE.

Keywords: MRI; Spectroscopy; Diagnosis; Prostate cancer; Prostatectomy.

Resum o Objetivo: Comparar as predições de tumor com padrão 4 de Gleason dominante ou de tumor com extensão extraprostática utilizando o sistema Prostate Imaging Reporting and Data System (PI-RADS v2), combinado ou não a espectroscopia por ressonância magnética $\left({ }^{1} \mathrm{H}\right.$-ERM).

Materiais e Métodos: Trinta e nove pacientes submeteram-se a RM de 3 tesla com bobina endorretal, incluindo ${ }^{1} \mathrm{H}$-ERM, e prostatectomia. Dois radiologistas classificaram as principais lesões identificadas em cada caso utilizando PI-RADS v2 e escores de ${ }^{1} \mathrm{H}$-ERM. As análises estatísticas incluíram regressões logísticas, curvas receiver operating characteristic (ROC) e tabelas $2 \times 2$ para acurácia diagnóstica.

Resultados: A sensibilidade e a especificidade da ${ }^{1} \mathrm{H}$-ERM e do PI-RADS v2 para a detecção de câncer de próstata de alto grau foram $85,7 \%$ (57,1\%) e 92,9\% (100\%), e 56\% (68\%) e 24\% (24\%). A sensibilidade e a especificidade da ${ }^{1} \mathrm{H}$-ERM e do PI-RADS v2 para a detecção de extensão extraprostática (EEP) foram 64,0\% (40\%) e 20\% (48\%), e 50\% (57,1\%) e 71,4\% (64,3\%). As áreas das curvas ROC para a predição de câncer de alto grau foram 0,65 e 0,61 para PI-RADS v2 e 0,72 e 0,70 quando combinado com ${ }^{1} \mathrm{H}$ -ERM (radiologistas 1 e 2, $p=0.04$ e 0.21). Para a predição de EEP, as áreas das curvas ROC foram 0,54 e 0,60 para PI-RADS v2 e 0,55 e 0,61 quando combinado com ${ }^{1} \mathrm{H}$-ERM ( $p>0.05$ ).

Conclusão: É possível que a ${ }^{1} \mathrm{H}$-ERM melhore a predição de câncer de alto grau quando combinada ao PI-RADS v2, em particular para lesões que recebem um escore PI-RADS v2 4; entretanto, ela não afeta a predição de EEP.

Unitermos: Espectroscopia; Diagnóstico; Câncer de próstata; Prostatectomia.

Study conducted in the Department of Radiology and Biomedical Imaging and in the Department of Urology, University of California San Francisco, San Francisco, CA, USA. This study was partly supported by NIH Grant R01CA137207.

1. MD, Department of Urology, University of California San Francisco, San Francisco, CA, USA.

2. MD, Department of Radiology and Biomedical Imaging, University of California San Francisco, San Francisco, CA, USA.

3. PhD, Department of Radiology and Biomedical Imaging, University of California San Francisco, San Francisco, CA, USA.
4. MPH, MD, Department of Urology, University of California San Francisco, San Francisco, CA, USA.

5. MD, PhD, Department of Radiology and Biomedical Imaging and Department of Urology, University of California San Francisco, San Francisco, CA, USA.

Mailing address: Antonio C. Westphalen, MD, PhD. Department of Radiology and Biomedical Imaging, University of California San Francisco. 505 Parnassus Avenue, M-372 San Francisco, CA, 94143, USA. E-mail: antonio.westphalen@ucsf.edu.

Received July 7, 2016. Accepted after revision November 3, 2016. 


\section{INTRODUCTION}

Prostate cancer (PCa) is diagnosed in approximately 230,000 men in the United States each year ${ }^{(1)}$, the majority of whom will possess favorable risk disease and in whom conservative approaches including active surveillance may be prudent ${ }^{(2)}$. Multiparametric magnetic resonance imaging (mpMRI) of the prostate has gained considerable utilization in the setting of newly diagnosed disease to identify occult, higher-grade or stage elements missed by conventional biopsy ${ }^{(3,4)}$. Moreover, when coupled with real time ultrasonography, fusion mpMRI biopsy has demonstrated superior PCa detection rates compared with traditional template guided biopsy ${ }^{(5)}$.

With growing integration of mpMRI as an adjunct diagnostic modality, the need to standardize acquisition protocols and study reporting is evident as it may facilitate benchmarks for consistency in both clinical care and research settings alike ${ }^{(6)}$. The American College of Radiology, the AdMeTech Foundation, and the European Society of Urogenital Radiology have partnered and recently presented a new version of the Prostate Imaging Reporting and Data System (PI-RADS v2), which integrates results of T2-weighted (T2W), high b-value diffusion-weighted image (DWI), and dynamic contrast enhanced (DCE) $\mathrm{MRI}^{(7)}$. Proton MR spectroscopic imaging $\left({ }^{1} \mathrm{H}-\mathrm{MRSI}\right)$, previously an optional tool, was not included in the current version of the document. ${ }^{1} \mathrm{H}$-MRSI has, though, been recognized as a useful non-invasive method for evaluating metabolic characteristics of prostatic lesions, yielding identifiable signatures that may allow for the discrimination of high-grade tumors ${ }^{(8)}$. However, ${ }^{1} \mathrm{H}-$ MRSI is susceptible to false positive related to choline contamination from the seminal vesicles or urethra ${ }^{(9)}$, or by prostatitis ${ }^{(10)}$. Furthermore, the ACRIN 6659 study that was published by Weinreb et al. found no added benefit for ${ }^{1} \mathrm{H}$-MRSI compared with T2W alone to localize $\mathrm{PCa}$ to the gland sextant ${ }^{(11)}$.

In this context, we sought to compare the diagnostic performance of PI-RADS v2 with or without ${ }^{1} \mathrm{H}$-MRSI for predicting PCa with dominant Gleason pattern $\geq 4$ or non-organ confined disease at the time of surgery.

\section{MATERIALS AND METHODS}

The Institutional Review Board approved this retrospective single center study. Informed consent was prospectively obtained from all patients authorizing the use of clinical data in future studies. Consecutive subjects were identified through searches of our Urological Oncological Database, Prostate MR Imaging Database, and electronic medical records. Inclusion criteria: biopsyproven PCa; 3-tesla endorectal prostate mpMRI, including ${ }^{1} \mathrm{H}$-MRSI; radical prostatectomy within six months of imaging; no treatments between imaging and surgery.

Forty patients seen between January 2013 and December 2014 fulfilled these criteria, but one was excluded because of a hip replacement that distorted the ${ }^{1} \mathrm{H}$-MRSI data. Therefore, 39 men formed the study population. Patients were clinically risk stratified using the Cancer of the Prostate Risk Assessment score (CAPRA) ${ }^{(12)}$. CAPRA is an easy to calculate validated nomogram that predicts outcomes across multiple treatment approaches and it predicts an individual's likelihood of metastasis, cancerspecific mortality, and overall mortality. The score is calculated using points assigned to: age at diagnosis, PSA at diagnosis, Gleason score of the biopsy, clinical stage and percent of biopsy cores involved with cancer. Three categories were assigned: low (scores $0-2$ ), intermediate (scores 3-5), and high risk (scores 6-10).

\section{MRI technique}

Scans were acquired on a 3-tesla scanner (GE Healthcare, Waukesha, WI, USA) using the body coil for excitation and an endorectal coil (E-Coil; Medrad, Pittsburgh, PA, USA) filled with perfluorocarbon (Flutech_T14 TM; F2 Chemicals, UK) and a phased-array coil for reception. Images were post-processed to compensate for the reception profile of the endorectal coil ${ }^{(13)}$.

The protocol included:

- Oblique axial T2W high-resolution 2D FSE MR images (thickness/gap $=3 \mathrm{~mm} / 0 \mathrm{~mm} ; \mathrm{TR} / \mathrm{TE}=5600-7400$ $\mathrm{ms} / 96-114 \mathrm{~ms} ; \mathrm{ETL}=16 ; \mathrm{FOV}=180 \mathrm{~mm} \times 180 \mathrm{~mm}$; reconstructed matrix $512 \times 512$; frequency direction $\mathrm{AP}$, $1 \mathrm{NEX})$. Acquisition time $=4 \mathrm{~min} 1 \mathrm{~s}$.

- Axial CUBE T2W 3D FSE MR images (thickness/ gap $=1.6 \mathrm{~mm} / 0 \mathrm{~mm} ; \mathrm{TR} / \mathrm{TE}=2400 \mathrm{~ms} / 142.4 \mathrm{~ms} ; \mathrm{ETL}$ $=90 ; \mathrm{FOV}=180 \mathrm{~mm} \times 180 \mathrm{~mm} ; 512 \times 512$ interpolated matrix in-plane and 2 -fold along the craniocaudal axis; frequency direction AP, $2 \mathrm{NEX}$; flip angle $=90^{\circ}$; receiver bandwidth $=90.91 \mathrm{kHz}$ ). Coronal and sagittal reformats were generated. Acquisition time $=4 \min 42 \mathrm{~s}$.

- Two 2D single-shot EPI SE high b-value DWI acquisitions (thickness/gap $=3 \mathrm{~mm} / 0 \mathrm{~mm} ; \mathrm{TR} / \mathrm{TE}=4725$ $\mathrm{ms} / \mathrm{minimum}$; FOV $=180 \mathrm{~mm} \times 180 \mathrm{~mm} ; 128 \times 64$; bvalues 0 and 600 and 0 and 1350). Acquisition times = 3 min $52 \mathrm{~s}$ and $4 \min 29 \mathrm{~s}$. Two ADC maps were reconstructed from each acquisition.

- Oblique axial T1-weighted 3D spoiled gradient echo dynamically contrast enhanced MR images (thickness $/$ gap $=3 \mathrm{~mm} / 0 \mathrm{~mm} ; \mathrm{TR} / \mathrm{TE}=$ minimum $/$ minimum; FOV $=260 \mathrm{~mm} \times 260 \mathrm{~mm} ; 192 \times 128 ; 1 \mathrm{NEX}$; gadopentetate dimeglumine, $0.1 \mathrm{mmol} / \mathrm{kg}$ of body weight, at a rate of $3 \mathrm{~cm}^{3} / \mathrm{s}$ using a power injector, followed by a $20 \mathrm{~cm}^{3}$ saline bolus at the same rate, $5 \mathrm{~min}$ acquisition, temporal resolution $=10 \mathrm{~s}$ ). Acquisition time $=4 \min 58 \mathrm{~s}$.

- 3D ${ }^{1} \mathrm{H}$-MRSI using a water and lipid-suppressed double-spin-echo point resolved spectroscopy sequence (MLEV-PRESS) with spectral-spatial pulses for the two $180^{\circ}$ excitation pulses, and outer-voxel saturation pulses (thickness $/$ gap $=3 \mathrm{~mm} / 0 \mathrm{~mm}$; TR/TE $=2000 \mathrm{~ms} / 85 \mathrm{~ms}$; $\mathrm{NEX}=1 ;$ phase encoding steps $=16 \times 10 \times 8 ; \mathrm{FOV}=$ 
$86 \times 54 \times 43 \mathrm{~mm}^{3}$ yielding a nominal spatial resolution of $0.16 \mathrm{~cm}^{3}$ ). A PRESS volume was selected using the oblique axial $\mathrm{T} 2 \mathrm{~W}$ images that incorporated the entire prostate while minimizing inclusion of the rectum and peri-prostatic lipids. The PRESS volume was shimmed using an automated phase mapping algorithm, followed by manual shimming of the $\mathrm{x}, \mathrm{y}$ and $\mathrm{z}$ gradients until a water line-width of $\leq 12 \mathrm{~Hz}$ was obtained. An interleaved flyback echo-planar spectroscopic readout with a spectral bandwidth of $1012 \mathrm{~Hz}$ was used in the left-right dimension. Acquisition time $=7 \mathrm{~min} 50 \mathrm{~s}$.

The ${ }^{1} \mathrm{H}$-MRSI data were processed using custom processing software ${ }^{(14)}$. The raw data acquired with the modified PRESS incorporating the flyback echo-planar readout trajectory were reordered as previously described ${ }^{(15)}$ and processed in the same manner as the conventional $4 \mathrm{D}{ }^{1} \mathrm{H}$-MRSI dataset ${ }^{(14)}$. The spectral data were apodized with a 2-Hz Lorentzian function in the frequency domain, with no filtering in the spatial dimensions. Data were Fourier transformed in the time domain and in three spatial domains. Spectral phase, baseline, and frequency corrections were iteratively made and metabolite peak areas calculated as previously described ${ }^{(14)}$. The $3 \mathrm{D}{ }^{1} \mathrm{H}-\mathrm{MRSI}$ spectral arrays and associated metabolite peak area ratios were overlaid on the corresponding transverse T2W images using the open-source spectral processing package SIVIC.

- Axial T1-weighted FGRE MR images (thickness/ gap $=4.2 \mathrm{~mm} / 0 \mathrm{~mm} ; \mathrm{TR} / \mathrm{TE}=5.06 \mathrm{~ms} / 2.46 \mathrm{~ms} ; \mathrm{FOV}=$ $240 \mathrm{~mm} \times 240 \mathrm{~mm} ; 192 \times 128 ; \mathrm{NEX}=1)$. Acquisition time $=2 \min 45 \mathrm{~s}$.

\section{Image interpretation}

Two radiologists (8 and 5 years of experience with ${ }^{1} \mathrm{H}$-MRSI and 2 years of experience with PI-RADS v2, i.e. since its initial publication), unaware of the clinical and pathologic data, independently reviewed all scans on a PACS workstation (Impax; Agfa, Mortsel, Belgium) in a single session. To mimic clinical practice, the radiologist could review the T2W, DWI, and DCE sequences in any order, alone or in conjunction. The radiologists had no access to ${ }^{1} \mathrm{H}$-MRSI images at this stage. Up to four suspicious foci were identified and PI-RADS v2 scores assigned to each (Table 1$)^{(7)}$.

Next the radiologists reviewed the 3D spectral arrays to assign a ${ }^{1} \mathrm{H}$-MRSI score to all suspicious lesions previously assigned a PI-RADS v2 score, i.e. lesions that received a PI-RADS v2 score ranging from 3 to 5. All usable voxels were scored using the five-point scale based on the area ratio of the citrate and choline peaks (Table 1). Figure 1 shows a representative case.

\section{Surgical technique and histologic evaluation}

Experienced urologists performed all radical prostatectomies. Pelvic lymph node dissection was performed based on pre-operative surgical risk. Prostatectomy specimens were marked with ink and fixed overnight in $10 \%$ buffered formalin. The glands were sectioned using whole-mount histology at $3 \mathrm{~mm}$ intervals in a plane perpendicular to the prostatic urethra. Experienced academic pathologists, unaware of imaging findings, reviewed the histological slides in all cases. The size, location, and Gleason score of all cancer foci seen in the prostate, and the presence, location, and extent of extra-prostatic disease were recorded.

\section{Statistical analysis}

The primary outcomes were the predictions of highgrade $\mathrm{PCa}$, defined as Gleason score $\geq 4+3$, and highstage disease, defined as extra-prostatic extension (EPE) $(\geq$ T3A) at radical prostatectomy on a per patient basis. In the event of multiple lesions, only the index lesion was considered for analyses. The index lesion was defined as the lesion with the highest overall PI-RADS score. If two or more lesions received the same score, the index lesion was the one associated with clear EPE. If none of the lesions demonstrated EPE, the index lesion was the largest one. We assessed the sensitivity, specificity, negative predictive value (NPV), positive predictive value (PPV), and accuracy of the overall PI-RADS v2 score and ${ }^{1} \mathrm{H}$-MRSI score assigned to suspicious lesions for the detection of these outcomes. For high-grade disease, the overall PIRADS v2 scores 1 to 3 were considered a negative result. For non-organ confined PCa, the overall PI-RADS v2 scores 1 to 4 were considered a negative result. This was because the presence of EPE on mpMRI determines an overall PI-RADS v2 score of 5 . For both analyses, ${ }^{1} \mathrm{H}$ MRSI was dichotomized as negative (score $\leq 3$ ) or positive (score 4 or 5 ).

We compared the areas under the receiver operating characteristic (ROC) curve of univariate logistic regression models that included the overall PI-RADS v2 score or ${ }^{1} \mathrm{H}$-MRSI score; and those to the area under the ROC curve derived from the multivariate models that included the overall PI-RADS v2 and ${ }^{1} \mathrm{H}-\mathrm{MRSI}$ scores. As mentioned above, if more than one lesion was suspected on mpMRI, only the index lesion was utilized in the analyses.

Interobserver agreement of overall PI-RADS v2 and ${ }^{1} \mathrm{H}$-MRSI scores were calculated utilizing a weighted kappa score $($ weights $=1 / 1-1 / 0.25-0.25-1 / 0-0-0.75-1$ $/ 0-0-0.5-0.75-1)$.

All analyses were performed using Stata version 13.1 (College Station, TX). $P$ values $<0.05$ were considered statistically significant.

\section{RESULTS}

The median age was 65 years (interquartile range (IQR), 11). The median PSA at diagnosis was $6.8 \mathrm{ng} / \mathrm{mL}$ (IQR, 5.1). CAPRA classified 13 men (33.3\%) with low, $21(53.9 \%)$ with intermediate, and $5(12.8 \%)$ with high 
Table 1-Distribution of imaging findings according to PI-RADS v2 criteria and ${ }^{1} \mathrm{H}-\mathrm{MRSI}$.

\begin{tabular}{|c|c|c|c|c|}
\hline \multirow[b]{2}{*}{ Sequence } & \multicolumn{2}{|c|}{ Reader 1} & \multicolumn{2}{|c|}{ Reader 2} \\
\hline & $\mathrm{N}$ & $(\%)$ & $\mathrm{N}$ & $(\%)$ \\
\hline \multicolumn{5}{|l|}{ T2W - Peripheral zone } \\
\hline 1 - Uniform hyperintense signal intensity (normal) & 0 & (0) & 0 & (0) \\
\hline 2 - Linear or wedge-shaped hypointensity/diffuse mild hypointensity, usually indistinct margin & 1 & $(3.5)$ & 0 & (0) \\
\hline 3 - Heterogenous signal intensity or non-circumscribed rounded, moderate hypointensity & 11 & $(37.9)$ & 5 & $(19.3)$ \\
\hline 4 - Circumscribed, homogenous moderate hypointense focus/mass confined to prostate and $<1.5 \mathrm{~cm}$ in greatest dimension & 14 & $(48.3)$ & 11 & $(42.3)$ \\
\hline 5 - As above, but $\geq 1.5 \mathrm{~cm}$ in greatest dimension or definitive extra-prostatic extension/invasive behavior & 3 & $(10.3)$ & 10 & $(38.5)$ \\
\hline \multicolumn{5}{|l|}{ T2W - Transition zone } \\
\hline 1 - Homogeneous intermediate signal intensity (normal) & 0 & (0) & 0 & (0) \\
\hline 2 - Circumscribed hypointense or heterogeneous encapsulated nodule(s) (benign prostatic hyperplasia) & 0 & (0) & 0 & (0) \\
\hline 3 - Heterogeneous signal intensity with obscured margins; includes others that do not qualify as 2,4 , or 5 & 1 & $(12.5)$ & 1 & $(10.0)$ \\
\hline 4 - Lenticular or non-circumscribed, homogeneous, moderately hypointense, and $<1.5 \mathrm{~cm}$ in greatest dimension & 2 & $(25.0)$ & 1 & $(10.0)$ \\
\hline 5 - As above, but $\geq 1.5 \mathrm{~cm}$ in greatest dimension or definite extraprostatic extension/invasive behavior & 5 & $(62.5)$ & 8 & $(80.0)$ \\
\hline \multicolumn{5}{|l|}{ DWI } \\
\hline 1 - No abnormality & 2 & $(5.1)$ & 3 & $(7.7)$ \\
\hline 2 - Indistinct hypointensity on ADC & 0 & $(0)$ & 0 & $(0)$ \\
\hline 3 - Focal mildly/moderately hypointense on ADC and isointense/mildly hyperintense on high b-value DWI & 4 & $(10.3)$ & 8 & $(20.5)$ \\
\hline 4 - Focal markedly hypointense on ADC and markedly hyperintense on high b-value $\mathrm{DWI} ;<1.5 \mathrm{~cm}$ in greatest dimension & 23 & $(59.0)$ & 12 & $(30.8)$ \\
\hline 5 - As above, but $\geq 1.5 \mathrm{~cm}$ in greatest dimension or definite extraprostatic extension/invasive behavior & 10 & $(25.6)$ & 16 & $(41.0)$ \\
\hline \multicolumn{5}{|l|}{ DCE } \\
\hline $\begin{array}{l}\text { (-) No early enhancement; or diffuse enhancement not corresponding to a focal finding on T2 and/or DWI; or focal enhance- } \\
\text { ment corresponding to a lesion demonstrating features of benign prostatic hyperplasia on T2WI }\end{array}$ & 11 & $(28.2)$ & 14 & $(35.9)$ \\
\hline $\begin{array}{l}\text { (+) focal, and; earlier than contemporaneously with enhancement of adjacent normal prostate tissue, and; corresponds to } \\
\text { suspicious finding on T2W and/or DWI }\end{array}$ & 28 & $(71.8)$ & 25 & $(64.1)$ \\
\hline \multicolumn{5}{|l|}{ Overall score } \\
\hline 1 - Very low (clinically significant cancer is highly unlikely to be present) & 0 & $(0)$ & 0 & $(0)$ \\
\hline 2 - Low (clinically significant cancer is unlikely to be present) & 2 & $(5.1)$ & 3 & $(7.7)$ \\
\hline 3 - Intermediate (the presence of clinically significant cancer is equivocal) & 5 & $(12.8)$ & 3 & $(7.7)$ \\
\hline 4 - High (clinically significant cancer is likely to be present) & 23 & $(59.0)$ & 16 & $(41.0)$ \\
\hline 5 - Very high (clinically significant cancer is highly likely to be present) & 9 & $(23.1)$ & 17 & $(43.6)$ \\
\hline \multicolumn{5}{|l|}{${ }^{1} \mathrm{H} M R S I$} \\
\hline 1 - Citrate:choline ratio $\geq 2$ & 3 & $(7.7)$ & 3 & $(7.7)$ \\
\hline 2 - Citrate:choline ratio $1-2$ & 5 & $(12.8)$ & 8 & $(20.5)$ \\
\hline 3 - Choline=citrate & 8 & $(20.5)$ & 12 & $(30.8)$ \\
\hline 4 - Choline:citrate ratio $1-2$ & 22 & $(56.4)$ & 13 & (33.3) \\
\hline 5 - Choline:citrate ratio $\geq 2$ & 1 & $(2.6)$ & 3 & $(7.7)$ \\
\hline
\end{tabular}

$\mathrm{N}$, number of patients.

clinical risk. Thirty-seven men $(94.8 \%)$ had clinically organ-confined disease at diagnosis; and $28(71.8 \%)$ had biopsy Gleason score $\leq 3+4$. The complete clinical, demographic and pathologic characteristics are presented in Table 2.

At prostatectomy, 5 men $(12.8 \%)$ had Gleason score $3+3,20(51.3 \%)$ had Gleason score 3+4, 12 had Gleason score $4+3(30.8 \%), 1(2.6 \%)$ had Gleason score $4+4$, and $1(2.6 \%)$ had Gleason score 5+4. Disease was organ-confined (T2C or less) in 19 (48.7\%). Twenty men (51.3\%) had extra-prostatic extension.

Table 1 reports the complete distribution of imaging findings for both readers; the weighted kappa of the overall PI-RADS v2 and of ${ }^{1} \mathrm{H}$-MRSI scores were 0.62 (95\% confidence interval: $0.47-0.81 ; 88.8 \%$ agreement) and
0.46 (95\% confidence interval: $0.22-0.70 ; 76.9 \%$ agreement), respectively.

The specificity of ${ }^{1} \mathrm{H}$-MRSI (assigned to a suspicious lesion) to predict Gleason pattern $\geq 4+3$ was higher than the specificity of the overall PI-RADS v2 score $(56.0 \%$, reader 1 , and $68.0 \%$, reader 2 , versus $24 \%$, both readers). For the detection of stage $\geq \mathrm{T} 3 \mathrm{a}$, the use of ${ }^{1} \mathrm{H}$-MRSI scores to further characterize suspicious lesions led, for reader 1 , to an increase in sensitivity (64\% versus 20\%) associated with a decrease in specificity $(50 \%$ versus $71.4 \%)$. No clear differences were seen for reader 2 . The performance characteristics are outlined in Table 3.

Table 4 details the AUCs for the prediction of Gleason pattern $\geq 4+3$ and extraprostatic disease. These results are also illustrated in Figure 2. 

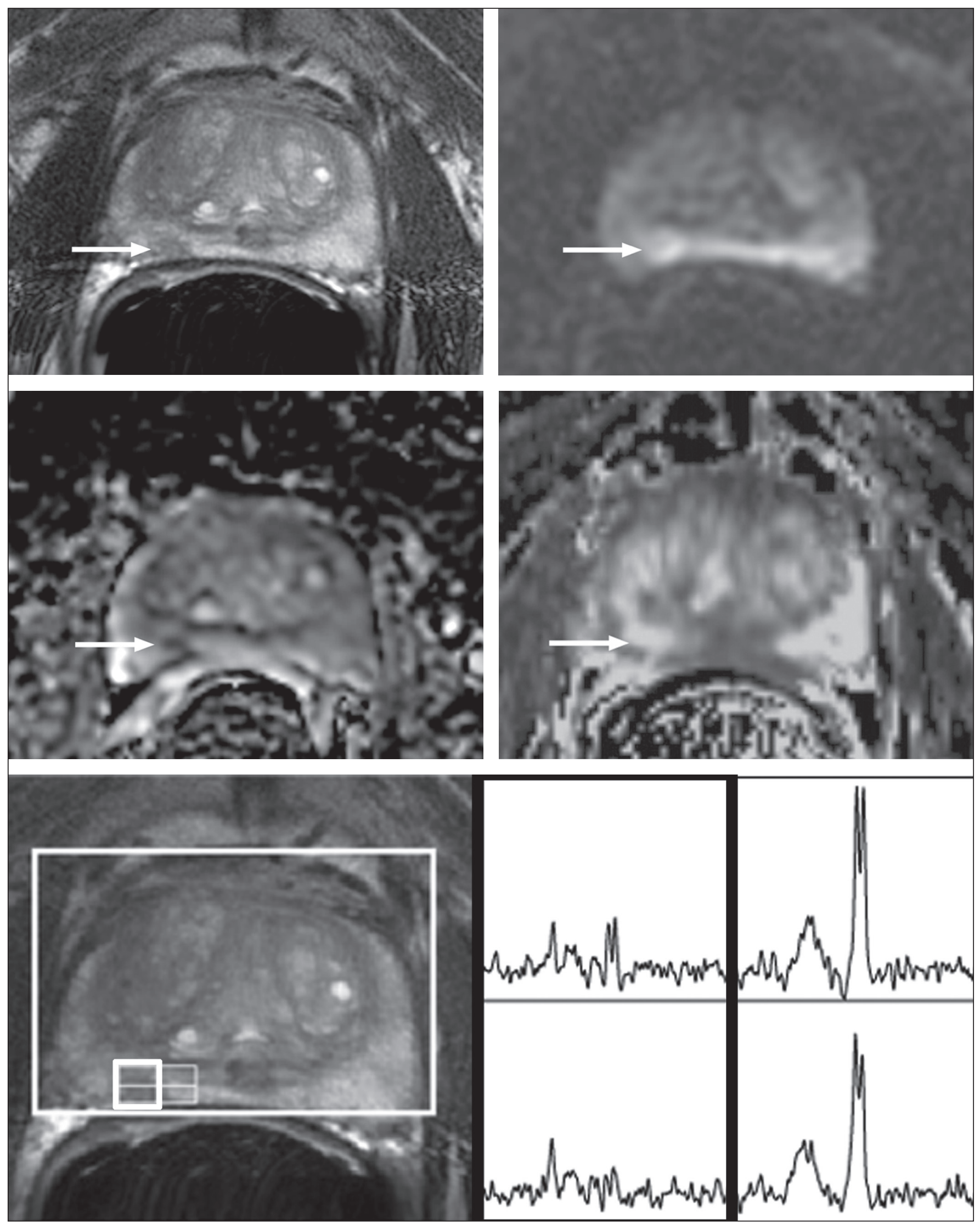

Figure 1. 73-year-old man with Gleason $4+3$ prostate cancer in the right posterior peripheral zone on radical prostatectomy, corresponding to the findings on imaging (arrows). Reader 1 (and reader 2) characterized the lesion as T2 $=3(4)$, DWI $=4$ (4), DCE = negative (positive), and overall PI-RADS v2 score $=4(4)$. Both readers assigned it a MRSI score of 4 (outlined voxels). 
Table 2-Baseline population characteristics.

\begin{tabular}{lc}
\hline Variable & Statistic \\
\hline Age at diagnosis, median (IQR, range) & $65(11,45-75)$ \\
PSA, ng/ml, median (IQR, range) & $6.8(5.1,1.62-16)$ \\
PSA density, median (IQR, range) & $0.20(0.15,0.06-0.65)$ \\
Clinical stage (digital rectal examination), N (\%) & \\
T1c & $11(28.2)$ \\
T2a & $25(64.1)$ \\
T2b & $1(2.6)$ \\
T3a & $1(2.6)$ \\
T3b & $1(2.6)$ \\
Diagnosis biopsy Gleason grade, N (\%) & \\
3+3 & $9(23.1)$ \\
3+4 & $19(48.7)$ \\
$4+3$ & $8(20.5)$ \\
$4+4$ & $1(2.6)$ \\
$5+4$ & $1(2.6)$ \\
$5+5$ & $1(2.6)$ \\
Number of diagnostic cores taken, median (IQR, & \\
range) & $25(29,8-50)$ \\
Percentage of positive diagnostic cores, median & \\
CAPRA range) & \\
0-2 (low risk) & \\
\hline
\end{tabular}

IQR, interquartile range; PSA, prostate specific antigen; N, number of patients.

Analysis of the shape of the ROC curves shows that the addition of ${ }^{1} \mathrm{H}$-MRSI to PI-RADS v2 improves the prediction of high-grade PCa when lesions are characterized as PI-RADS v2 score 4. There were no statistically significant differences between the AUC of overall PI-RADS v2 (0.65, reader 1 ; and 0.61 , reader 2 ) and ${ }^{1} \mathrm{H}$-MRSI (0.75, reader 1 ; and 0.70 , reader 2 ) for either reader. The AUC of overall PI-RADS v2 combined with ${ }^{1} \mathrm{H}$-MRSI was significantly higher than the AUC of overall PI-RADS v2 alone for reader $1(0.77 ; p=0.04)$, but not for reader $2(0.70 ; p=0.21)$.

For the discrimination of stage $\geq \mathrm{T} 3 \mathrm{a}$, there were no statistically significant differences between the AUC of overall PI-RADS v2 (0.54, reader 1 ; and 0.60 , reader 2$)$, ${ }^{1}$ H-MRSI (0.61, reader 1 ; and 0.54 , reader 2$)$, and their combination $(0.55$, reader 1 ; and 0.61 , reader 2 ) for either reader.

\section{DISCUSSION}

Our results suggest that the addition of ${ }^{1} \mathrm{H}$-MRSI to PI-RADS v2 might improve the detection of PCa with Gleason pattern $\geq 4+3$, in particular of PI-RADS v2 score 4 lesions; however, it does not seem to increase the detection of high stage ( $\geq$ T3a) disease.

Different from its initial version, PI-RADS v2 does not include ${ }^{1} \mathrm{H}$-MRSI. Yet, the PI-RADS Steering Committee
Table 3-Diagnostic test characteristics of PI-RADS v2 and ${ }^{1} \mathrm{H}-\mathrm{MRSI}$ for the identification of high grade prostate cancer (dominant Gleason pattern $\geq 4$ ) and extraprostatic disease at radical prostatectomy.

\begin{tabular}{|c|c|c|c|c|}
\hline & $\begin{array}{l}\text { Sensitivity } \\
(95 \% \mathrm{Cl})\end{array}$ & $\begin{array}{l}\text { Specificity } \\
(95 \% \text { Cl) }\end{array}$ & $\begin{array}{c}\text { PPV } \\
(95 \% \mathrm{Cl})\end{array}$ & $\begin{array}{c}\text { NPV } \\
(95 \% \mathrm{Cl})\end{array}$ \\
\hline \multicolumn{5}{|c|}{ High grade prostate cancer (dominant Gleason pattern $\geq 4$ ) } \\
\hline & \multicolumn{4}{|c|}{ Reader 1} \\
\hline Overall PI-RADS 2 & $\begin{array}{c}92.9 \\
(66.1-99.8)\end{array}$ & $\begin{array}{c}24.0 \\
(9.4-45.1)\end{array}$ & $\begin{array}{c}40.6 \\
(23.7-59.4)\end{array}$ & $\begin{array}{c}85.7 \\
(42.1-99.6)\end{array}$ \\
\hline \multirow[t]{2}{*}{${ }^{1} \mathrm{H}$ MRSI } & $\begin{array}{c}85.7 \\
(57.2-98.2)\end{array}$ & $\begin{array}{c}56.0 \\
(34.9-75.6)\end{array}$ & $\begin{array}{c}52.2 \\
(30.6-73.2)\end{array}$ & $\begin{array}{c}87.5 \\
(61.7-98.4)\end{array}$ \\
\hline & \multicolumn{4}{|c|}{ Reader 2} \\
\hline Overall PI-RADS 2 & $\begin{array}{c}100.0 \\
(76.8-100)\end{array}$ & $\begin{array}{c}24.0 \\
(9.4-45.1)\end{array}$ & $\begin{array}{c}42.4 \\
(25.5-60.8)\end{array}$ & $\begin{array}{c}100.0 \\
(54.1-100)\end{array}$ \\
\hline \multirow[t]{3}{*}{${ }^{1} \mathrm{H} M R S I$} & $\begin{array}{c}57.1 \\
(28.9-82.3)\end{array}$ & $\begin{array}{c}68.0 \\
(46.5-85.1)\end{array}$ & $\begin{array}{c}50.0 \\
(24.7-75.3)\end{array}$ & $\begin{array}{c}73.9 \\
(51.6-89.8)\end{array}$ \\
\hline & \multicolumn{4}{|c|}{ Extraprostatic disease (stage $\geq \mathrm{T} 3 \mathrm{a}$ ) } \\
\hline & \multicolumn{4}{|c|}{ Reader 1} \\
\hline Overall PI-RADS 2 & $\begin{array}{c}20.0 \\
(6.8-40.7)\end{array}$ & $\begin{array}{c}71.4 \\
(41.9-91.6)\end{array}$ & $\begin{array}{c}55.6 \\
(21.2-86.3)\end{array}$ & $\begin{array}{c}33.3 \\
(17.3-52.8)\end{array}$ \\
\hline \multirow[t]{2}{*}{${ }^{1} \mathrm{H} \mathrm{MRSI}$} & $\begin{array}{c}64.0 \\
(42.5-82.0)\end{array}$ & $\begin{array}{c}50.0 \\
(23.0-77.0)\end{array}$ & $\begin{array}{c}69.6 \\
(47.1-86.8)\end{array}$ & $\begin{array}{c}43.8 \\
(19.8-70.1)\end{array}$ \\
\hline & \multicolumn{4}{|c|}{ Reader 2} \\
\hline Overall PI-RADS 2 & $\begin{array}{c}48.0 \\
(27.8-68.7)\end{array}$ & $\begin{array}{c}64.3 \\
(35.1-87.2)\end{array}$ & $\begin{array}{c}70.6 \\
(44.0-89.7)\end{array}$ & $\begin{array}{c}40.9 \\
(20.7-63.6)\end{array}$ \\
\hline${ }^{1} \mathrm{H} \mathrm{MRSI}$ & $\begin{array}{c}40.0 \\
(21.1-61.3)\end{array}$ & $\begin{array}{c}57.1 \\
(28.9-82.3)\end{array}$ & $\begin{array}{c}62.5 \\
(35.4-84.8)\end{array}$ & $\begin{array}{c}34.8 \\
(16.4-57.3)\end{array}$ \\
\hline
\end{tabular}

95\% Cl, 95\% confidence interval.

Table 4-Performance of PI-RADS v2 and ${ }^{1} \mathrm{H}-\mathrm{MRSI}$, alone and combined, for the discrimination of high-grade prostate cancer (dominant Gleason pattern $\geq 4$ ) and extraprostatic disease at radical prostatectomy.

\begin{tabular}{|c|c|c|c|c|}
\hline \multirow[b]{2}{*}{ Model variables } & \multicolumn{2}{|c|}{ Reader 1} & \multicolumn{2}{|c|}{ Reader 2} \\
\hline & AUC & $95 \% \mathrm{Cl}$ & AUC & $95 \% \mathrm{Cl}$ \\
\hline \multicolumn{5}{|c|}{ Dominant Gleason pattern 4 or higher outcome } \\
\hline Overall PI-RADS 2 & 0.65 & $0.49-0.81$ & 0.61 & $0.45-0.77$ \\
\hline${ }^{1} \mathrm{H} \mathrm{MRSI}$ & 0.75 & $0.62-0.87$ & 0.70 & $0.55-0.86$ \\
\hline Overall PI-RADS $2+{ }^{1} \mathrm{H}$ MRSI & 0.77 & $0.63-0.91$ & 0.70 & $0.53-0.86$ \\
\hline \multicolumn{5}{|c|}{ Pathological stage T3a or higher outcome } \\
\hline Overall PI-RADS 2 & 0.54 & $0.34-0.73$ & 0.60 & $0.42-0.78$ \\
\hline${ }^{1} \mathrm{H} \mathrm{MRSI}$ & 0.61 & $0.43-0.79$ & 0.54 & $0.36-0.73$ \\
\hline Overall PI-RADS $2+{ }^{1} \mathrm{H}$ MRSI & 0.55 & $0.34-0.76$ & 0.61 & $0.43-0.80$ \\
\hline
\end{tabular}

95\% Cl, 95\% confidence interval.

encourages "the continued development of promising MRI methodologies", including ${ }^{1} \mathrm{H}-\mathrm{MRSI}^{(16)}$, and state that these technologies will be considered for inclusion in future versions, pending new data. While the PI-RADS v2 document does not provide specific reasons for not including ${ }^{1} \mathrm{H}$-MRSI, it is known that it is a complex technique with limited acceptance outside specialized centers due to its long acquisition time, need for local expertise, and general reliance on endorectal coil imaging. Yet, ${ }^{1} \mathrm{H}$ MRSI warrants continue attention; new hardware and software developments may make it more manageable. 


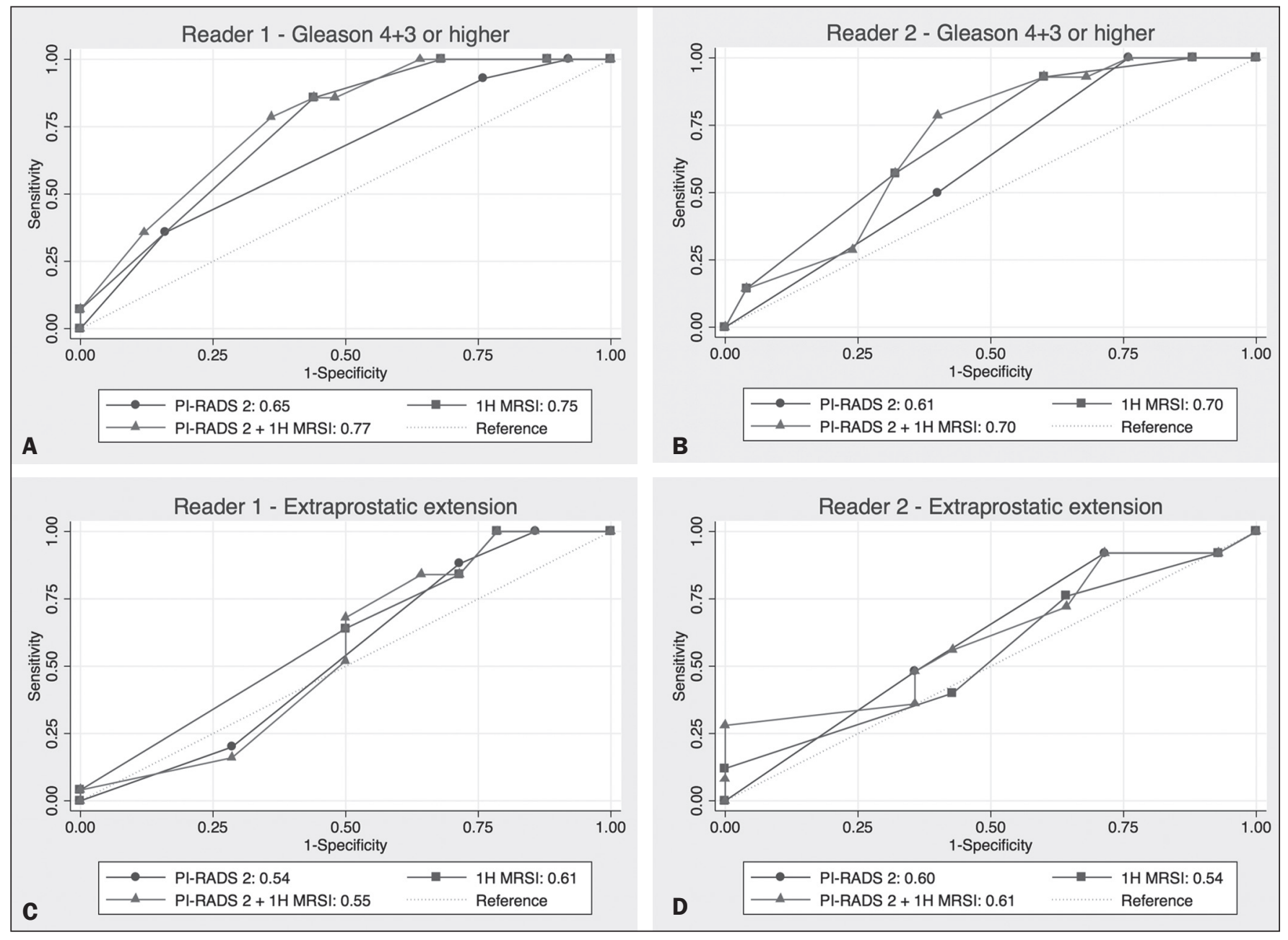

Figure 2. ROC curves for the prediction of pathological Gleason pattern 4 or higher disease (A,B) by the overall PI-RADS v2 score alone and PI-RADS v2 combined with ${ }^{1} \mathrm{H}$-MRSI. Images $\mathbf{C}$ and $\mathbf{D}$ depict the ROC curves for the prediction of non-organ confined disease (stage T3a or greater) by the same models.

Based on previous studies, ${ }^{1} \mathrm{H}-\mathrm{MRSI}$ improves tumor localization $^{(17,18)}$, volume estimation ${ }^{(19,20)}$, $^{\text {staging }}{ }^{(21)}$, tissue characterization ${ }^{(22)}$, and identification of recurrent disease after therapy ${ }^{(23,24)}$. A multicenter study showed that positive MR spectroscopy findings are likely to reflect higher tumor grade and/or volume ${ }^{(25)}$. These studies, though, do have limitations, and there are, also, those with less encouraging results; the ACRIN study published in 2009, for example, showed no difference of accuracy when comparing combined T2W and ${ }^{1} \mathrm{H}-\mathrm{MRSI}$ and T2W alone $^{(11)}$.

Our results show that the overall PI-RADS v2 score is very sensitive to detect Gleason pattern $\geq 4+3$, but its specificity is very low. This suggests PI-RADS v2 is a good option to detect the disease, but not necessarily to characterize it. The use of ${ }^{1} \mathrm{H}$-MRSI, however, led to a $50 \%$ increase in specificity, and might at least in some cases help to identify men with high-grade PCa. Our results showed this is particularly true when a lesion receives a PI-RADS v2 score of 4 . These results are aligned to those of Giusti et al., who showed that metabolic ratios correlate with Gleason scores ${ }^{(26)}$, and they are similar to those of a meta- analysis in which ${ }^{1} \mathrm{H}$-MRSI had a higher specificity than T2W and increased the specificity of the combination of $\mathrm{T} 2 \mathrm{~W}$ and $\mathrm{DWI}^{(18)}$. While the comparison of overall AUCs (i.e. summary of data for all lesions) found an improvement of discrimination between men with and without PCa Gleason pattern $\geq 4+3$ using the combined PI-RADS v2 and ${ }^{1} \mathrm{H}$-MRSI for one reader only, the assessment of the shape of the curves shows a clear separation between the lines of the ROC curves of PI-RADS v2 alone and PI-RADS v2 combined with ${ }^{1} \mathrm{H}$-MRSI at the segment that includes only PI-RADS v2 score 4 lesions for both readers. It is possible that this discrepancy in results is due to differences in readers' experience. ${ }^{1} \mathrm{H}$-MRSI is a complex technique and interpretation can be challenging. It is important to make note of this fact, as these same challenges are likely to be found at other sites that lack radiologist with experience with ${ }^{1} \mathrm{H}$-MRSI.

The metabolic nature of ${ }^{1} \mathrm{H}$-MRSI might explain why it did improve the detection of EPE, as EPE is typically detected on anatomical images. The overall PI-RADS v2 score, however, does include an anatomical assessment. Furthermore, both readers assigned an overall PI-RADS 
score of 4 or 5 to more than $80 \%$ of these suspicious lesions, and an overall PI-RADS v2 score of 5, at least in some instances, characterizes definite $\mathrm{EPE}^{(16)}$. An increase in specificity after utilizing ${ }^{1} \mathrm{H}$-MRSI might, therefore, not have been expected. Similarly, because ${ }^{1}$ H-MRSI was applied after the detection of a suspicious lesion using PIRADS $v 2$, its sensitivity is a direct reflection of this initial detection. Accordingly, it would be expected that positive ${ }^{1} \mathrm{H}$-MRSI results would have a greater impact on lower overall PI-RADS v2 scores. In this study we opted for analyzing only the index lesion, less than $20 \%$ of which received a score of 3, likely explaining the lack of benefit of ${ }^{1} \mathrm{H}$-MRSI. It remains, thus, unknown if ${ }^{1} \mathrm{H}$-MRSI would have affected cases presenting with these indeterminate lesions.

We did not find other studies evaluating the incorporation ${ }^{1} \mathrm{H}$-MRSI to PI-RADS v2, but a few authors tested it with its previous version with various results. The studies of Khalifa et al. ${ }^{(27)}$ and Panebianco et al. ${ }^{(28)}$ suggested ${ }^{1} \mathrm{H}$-MRSI improved characterization of PCa and support our results. Yet, the results of Platzek et al. ${ }^{(29)}$ and, more recently, Polanec et al. ${ }^{(30)}$ found that ${ }^{1} \mathrm{H}$-MRSI did not increase the detection and nor improved the grading of PCa. While several possible explanations exist for these discrepancies, the exercise of explaining them is likely not warranted, as the first version of PI-RADS is quite different from PI-RADS v2 and should no longer be utilized. More important, perhaps, is to recognize that considerable interest exists in optimizing the identification high grade or stage disease among men with clinically localized $\mathrm{PCa}$ as such determinations may improve management decisions. And that other imaging techniques, including ${ }^{1} \mathrm{H}$-MRSI, may be helpful.

This study has limitations. First, this was a retrospective study with the limitations inherent to this type of design. The population studied was highly selected and included only men who had endorectal mpMRI and radical prostatectomy. We, therefore, probably incurred selection bias and our patients may not fully represent all men with PCa. This is illustrated by the fact most of our lesions were characterized as PI-RADS v2 4 and 5, as men with lower scores are less likely to have cancer and to undergo surgery. However, we considered the need for an adequate standard of reference more important than the limited generalizability. One possible option to prostatectomy is MR-guided biopsy, which can be performed in-bore or by fusion with ultrasound. Accordingly, some of our results, in particular the positive and negative predictive values, do not apply to all men with suspected PCa nor to all men who are under active surveillance and typically have low-grade low-volume disease. Second, we examined endpoints of high-grade and/or non-organ confined disease, but not more distant oncologic endpoints including biochemical recurrence or metastatic progression. Prospective studies with extended follow up may be warranted to definitively evaluate the role of ${ }^{1} \mathrm{H}$-MRSI in improved delineation of PCa outcomes. Third, PI-RADS was designed with the intent to improve the detection of tumors with Gleason score $\geq 3+4$, and not $\geq 4+3$ as we proposed. This could, perhaps, explain the low specificity of PI-RADS v2 found in this study. More important, though, is that we may have overestimated the diagnostic performance of both PI-RADS v2 and ${ }^{1} \mathrm{H}$-MRSI due to spectrum bias. Spectrum bias refers to the fact that it is usually easier to detect advanced disease than early-stage disease, as subtle abnormalities can be hard to distinguish from normal findings. This typically leads to a higher diagnostic accuracy when a study includes in a population with advanced disease than when the subjects have less severe disease. We opted for characterizing as high-grade tumors only tumors with Gleason score $\geq 4+3$ because many institutions consider men with Gleason $3+4$ as candidates for active surveillance, while a Gleason score $\geq$ $4+3$ is universally considered an indication for definitive therapy.

In summary, ${ }^{1} \mathrm{H}$-MRSI might improve the discrimination of pathological Gleason score $\geq 4+3$ when added to the PI-RADS $\mathrm{v} 2$, in particular for lesions that receive a score of 4 , but it does not affect the prediction of $\mathrm{PCa}$ stage $\geq$ T3a.

\section{REFERENCES}

1. Siegel RL, Miller KD, Jemal A. Cancer statistics, 2015. CA Cancer J Clin. 2015;65:5-29.

2. Glass AS, Cowan JE, Fuldeore MJ, et al. Patient demographics, quality of life, and disease features of men with newly diagnosed prostate cancer: trends in the PSA era. Urology. 2013;82:60-5.

3. Wysock JS, Rosenkrantz AB, Huang WC, et al. A prospective, blinded comparison of magnetic resonance (MR) imaging-ultrasound fusion and visual estimation in the performance of MR-targeted prostate biopsy: the PROFUS trial. Eur Urol. 2014;66:343-51.

4. Pokorny MR, de Rooij M, Duncan E, et al. Prospective study of diagnostic accuracy comparing prostate cancer detection by transrectal ultrasound-guided biopsy versus magnetic resonance (MR) imaging with subsequent MR-guided biopsy in men without previous prostate biopsies. Eur Urol. 2014;66:22-9.

5. Siddiqui MM, Rais-Bahrami S, Turkbey B, et al. Comparison of MR/ultrasound fusion-guided biopsy with ultrasound-guided biopsy for the diagnosis of prostate cancer. JAMA. 2015;313:390-7.

6. Hamoen EH, de Rooij M, Witjes JA, et al. Use of the Prostate Imaging Reporting and Data System (PI-RADS) for prostate cancer detection with multiparametric magnetic resonance imaging: a diagnostic meta-analysis. Eur Urol. 2015;67:1112-21.

7. Weinreb JC, Barentsz JO, Choyke PL, et al. PI-RADS Prostate Imaging - Reporting and Data System: 2015, Version 2. Eur Urol. 2016;69:16-40.

8. Rais-Bahrami S, Siddiqui MM, Turkbey B, et al. Utility of multiparametric magnetic resonance imaging suspicion levels for detecting prostate cancer. J Urol. 2013;190:1721-7.

9. Verma S, Rajesh A, Futterer JJ, et al. Prostate MRI and 3D MR spectroscopy: how we do it. AJR Am J Roentgenol. 2010;194:1414-26.

10. Sciarra A, Panebianco V, Ciccariello M, et al. Magnetic resonance spectroscopic imaging (1H-MRSI) and dynamic contrast-enhanced magnetic resonance (DCE-MRI): pattern changes from inflammation to prostate cancer. Cancer Invest. 2010;28:424-32.

11. Weinreb JC, Blume JD, Coakley FV, et al. Prostate cancer: sextant 
localization at MR imaging and MR spectroscopic imaging before prostatectomy-results of ACRIN prospective multi-institutional clinicopathologic study. Radiology. 2009;251:122-33.

12. Cooperberg MR, Pasta DJ, Elkin EP, et al. The University of California, San Francisco Cancer of the Prostate Risk Assessment score: a straightforward and reliable preoperative predictor of disease recurrence after radical prostatectomy. J Urol. 2005;173:1938-42.

13. Noworolski SM, Reed GD, Kurhanewicz J, et al. Post-processing correction of the endorectal coil reception effects in MR spectroscopic imaging of the prostate. J Magn Reson Imaging. 2010;32:654-62.

14. Nelson SJ. Analysis of volume MRI and MR spectroscopic imaging data for the evaluation of patients with brain tumors. Magn Reson Med. 2001;46:228-39.

15. Chen AP, Cunningham CH, Ozturk-Isik E, et al. High-speed $3 \mathrm{~T}$ MR spectroscopic imaging of prostate with flyback echo-planar encoding. J Magn Reson Imaging. 2007;25:1288-92.

16. American College of Radiology. MR Prostate Imaging Reporting and Data System version 2.0. [cited 2016 Mar 15]. Available from: www.acr.org/Quality-Safety/Resources/PIRADS.

17. Umbehr M, Bachmann LM, Held U, et al. Combined magnetic resonance imaging and magnetic resonance spectroscopy imaging in the diagnosis of prostate cancer: a systematic review and metaanalysis. Eur Urol. 2009;55:575-90.

18. Zhang ZX, Yang J, Zhang CZ, et al. The value of magnetic resonance imaging in the detection of prostate cancer in patients with previous negative biopsies and elevated prostate-specific antigen levels: a meta-analysis. Acad Radiol. 2014;21:578-89.

19. Anwar M, Westphalen AC, Jung AJ, et al. Role of endorectal MR imaging and MR spectroscopic imaging in defining treatable intraprostatic tumor foci in prostate cancer: quantitative analysis of imaging contour compared to whole-mount histopathology. Radiother Oncol. 2014;110:303-8.

20. Chang S, Westphalen AC, Jha P, et al. Endorectal MRI and MR spectroscopic imaging of prostate cancer: developing selection criteria for MR-guided focused ultrasound surgery-preliminary experience. AJR Am J Roentgenol. 2011;196:A31-A35.

21. Yu K, Scheidler J, Hricak H, et al. Prostate cancer: prediction of extracapsular extension with endorectal MR imaging and three-dimensional proton MR spectroscopic imaging. Radiology. 1999;213:481-8.

22. Jung JA, Coakley FV, Vigneron DB, et al. Prostate depiction at endorectal MR spectroscopic imaging: investigation of a standardized evaluation system. Radiology. 2004;233:701-8.

23. Arrayeh E, Westphalen AC, Kurhanewicz J, et al. Does local recurrence of prostate cancer after radiation therapy occur at the site of primary tumor? Results of a longitudinal MRI and MRSI study. Int J Radiat Oncol Biol Phys. 2012;82:e787-93.

24. Westphalen AC, Coakley FV, Roach M 3rd, et al. Locally recurrent prostate cancer after external beam radiation therapy: diagnostic performance of 1.5-T endorectal MR imaging and MR spectroscopic imaging for detection. Radiology. 2010;256:485-92.

25. Shukla-Dave A, Hricak H, Akin O, et al. Preoperative nomograms incorporating magnetic resonance imaging and spectroscopy for prediction of insignificant prostate cancer. BJU Int. 2012;109:131522.

26. Giusti S, Caramella D, Fruzzetti E, et al. Peripheral zone prostate cancer. Pre-treatment evaluation with MR and 3D ${ }^{1} \mathrm{H}$ MR spectroscopic imaging: correlation with pathologic findings. Abdom Imaging. 2010;35:757-63.

27. Khalifa MHK, Hafez A, Elnoueam K, et al. Multi-parameteric MRI and PI-RADS scoring system: our new inception in clinical practice with evaluation of the diagnostic performance of different score combinations. Poster No. C-0590. European Congress of Radiology 2015. 4-8 March 2015. Vien, Austria.

28. Panebianco V, Barchetti F, Manenti G, et al. MR imaging-guided prostate biopsy: technical features and preliminary results. Radiol Med. 2015;120:571-8.

29. Platzek I, Borkowetz A, Toma M, et al. Multiparametric prostate magnetic resonance imaging at $3 \mathrm{~T}$ : failure of magnetic resonance spectroscopy to provide added value. J Comput Assist Tomogr. 2015;39:674-80.

30. Polanec SH, Pinker-Domenig K, Brader P, et al. Multiparametric MRI of the prostate at $3 \mathrm{~T}$ : limited value of 3D (1)H-MR spectroscopy as a fourth parameter. World J Urol. 2016;34:649-56. 